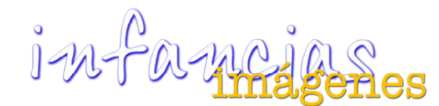

http://revistas.udistrital.edu.co/ojs/index.php/infancias

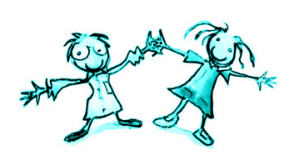

SEPARATA ESPECIAL

\title{
La literatura y los niños. Cuatro escolios imprescindibles
}

\author{
Beatriz Helena Robledo B. ${ }^{1}$
}

Se llama escolios (del latín scholium y este del griego $\sigma \chi \chi_{\text {}} \iota \mathrm{ov}$, "comentario") a las notas o breves comentarios gramaticales, críticos o explicativos, ya sean originales o extractos de comentarios existentes, que se insertan en los márgenes del manuscrito de un autor antiguo como glosa sucinta. (Wikipedia, s.f.)

En los más de 30 años que llevo recorriendo el mundo de la literatura infantil y su relación con los niños he hechos algunos hallazgos que quiero compartir con ustedes, no como verdades, sino como una invitación a reflexionar. Los iré presentando como escolios de un texto interior que se ha ido fraguando con los años a partir de lecturas, investigaciones y experiencias. La invitación es que sigan pensando esa relación vital que existe entre los niños y los libros, ya sea desde su interior o acompañados, glosando, conversando.

\section{Escolio}

El primer escolio surge de una frase reveladora que escuché decir hace algunos años a Evelio Cabrejo, psicoanalista colombiano especializado en la relación de los niños con la formación de su psiquismo y del lenguaje. Dijo Cabrejo: "Los niños necesitan, pan, afecto y literatura". Así, en el mismo plano. Pan para el cuerpo, afecto para su territorio emocional y su certeza afectiva, y literatura para su espíritu, su psique y su imaginario. La literatura alimenta al niño. El tiempo y el espacio simbólicos se nutren y logran que se desarrolle y fortalezca el pensamiento simbólico, es decir, la capacidad creativa. Está en nosotros, los adultos, ayudar a que se desarrolle esta capacidad. Infortunadamente, muchos de nuestros niños crecen con hambre de palabra simbólica. Esta carencia puede llegar incluso a atrofiar su capacidad metafórica, que no es otra cosa que el poder dirigir sus propios destinos a pesar de las adversidades que la vida les presente. Capacidad metafórica que los niños traen consigo casi de manera natural, como un campo de potencia creativa que debe ser nutrida para que se fortalezca y se exprese.

En una experiencia que tuve con niños de tercer grado, niños creciendo en ambientes pobres de pan, afecto y literatura, me encontré con una situación que me hizo comprender y ampliar la cita de Cabrejo. Estábamos haciendo un bestiario, que no fue fácil por el exceso de realismo en el que crecen estos niños; en una de las sesiones descubrí que muchos de ellos no podían imaginar los aretes que le faltan a la luna, esa hermosa imagen extraviada de un bolero.

Es grave que un niño crezca carente de metáforas, pues la esencia de la niñez es la capacidad de jugar. $Y$ es el juego el territorio natural de la metáfora. Cuando un niño juega inventa personajes, diálogos, escenarios diferentes a los de la vida real. Inventa un mundo paralelo que le da la posibilidad de apropiarse poco a poco del mundo real a través del lenguaje, pero también de un mundo que le da seguridad y que le entrega los recursos para

\footnotetext{
1 Escritora e investigadora en literatura y lectura. Magíster en Literatura Hispanoamericana de la Universidad Javeriana. Autora de obras de investigación y de ficción como Antología del relato infantil colombiano (1997), Antología de poesía juvenil colombiana (2000), Rafael Pombo, la vida de un poeta (2005), El arte de la mediación. Espacios y estrategias para la promoción de la lectura (2009), Viva la Pola (2010), Flores blancas para papá (2012) y Mi primer libro de poemas (2016). Ha recibido diferentes becas de investigación y ha participado en eventos internacionales en varios países. Actualmente dirige el Consultorio Lector, programa de atención personalizada en lectura, escritura y literatura.
} 
narrarse, para crearse un lugar que le pertenezca, un mundo habitable.

La literatura hace parte esencial de este territorio del juego. La primera relación que tienen los niños pequeños con la literatura puede surgir desde el vientre. Cuando la madre le canta o le cuenta al niño aun estando en su vientre le está generando las primeras experiencias literarias.

“Duerme, duerme negrito, que tu mama está en el campo negrito/ te va a traer codornices para ti/ te va a traer muchas cosas para ti $[. . .]^{\prime \prime}$. La esperanza del regreso de la madre cuando está ausente se siembra con este sencillo verso de la tradición oral, interpretado por Athaualpa Yupankui, quien la escuchó por primera vez de boca de una mujer morena del caribe entre Colombia y Venezuela. La literatura, expresada en canciones de cuna, arruIlos, nanas, cuentos, libros de imágenes, historias cotidianas, tiene efectos en las emociones, la psique, la imaginación y el inconsciente de los niños.

Los primeros efectos están relacionados con II nuestra inscripción en el tiempo. A través de la cadencia, la musicalidad y el ritmo de las canciones de cuna el niño pequeño incorpora pautas temporales más ricas y complejas que las marcas del tiempo cotidiano. Y como dice George Jean: "[...] La evidencia poética es mucho más una apertura, una fulguración de "otro espacio", y la 'continuidad de murmullo' de los cuentos y de las 'historias' invita a cierta conciencia paciente de nuestra inscripción en el tiempo" (1990, p. 15).

La literatura ayuda a los niños a construir el tiempo y el espacio imaginarios. Este cuerpo de palabras, sonidos, voces y cadencias entregados por el adulto al niño durante su infancia se convierte en reserva para toda la vida. Es un ciclo ecológico de preservación de la salud emocional que servirá no solo para disfrutar los años de niñez, sino también para acudir a esta en los momentos difíciles de la vida. La palabra poética, el lenguaje literario, la metáfora y la rima se inscriben en el cuerpo del niño, nutren su inconsciente y se quedan a vivir con él como un eco que resuena. Esta reserva, además de ayudar a configurar un tiempo y un espacio imaginarios, más allá del tiempo y el espacio concretos, abre la posibilidad de crear, lo que le permite al niño sentir que el mundo en el que vive puede ser diferente y que él es artífice de esa transformación. El hombre al nombrar el mundo se vuelve poderoso, se vuelve creador y es desde la infancia que el niño debe apropiarse de ese lenguaje que resulta mágico y que va más allá del lenguaje cotidiano necesario para comunicarse. El poder de la palabra mágica lo aporta la literatura y esta, por fortuna, es inmensamente rica y variada.

Quizás uno de los primeros beneficios que aporta la literatura desde la temprana infancia está relacionado con los vínculos afectivos entre padres e hijos. Cuando la madre arrulla al bebé y le canta le transmite amor y seguridad. Esa palabra es nicho que protege y es a la vez herencia cultural. Cuando la madre acoge al niño en el regazo y le cuenta un cuento o le muestra un libro de imágenes, el niño, además de aprender sobre el mundo, sobre las representaciones y los mundos imaginarios, aprehende el afecto y la caricia a través de la voz. Eso para un niño es vital. Hace parte del equipaje necesario para crecer seguro, sin vértigo, para crecer con las herramientas necesarias que le permitirán conjurar y vencer el miedo, para sentirse más seguro de sí mismo, para relacionarse amorosa y solidariamente con los demás. En los primeros años de vida, la literatura que se entrega a los niños tiene mucho más que ver con las situaciones afectivas, los escenarios y los ambientes que con los contenidos mismos. Para el niño es muy valioso ese momento en el cual tiene a su madre, a su padre, a su abuela, consigo y para sí, entregándole afecto con generosidad. Cuando somos adultos y hemos sido nutridos con literatura, recordamos no tanto la historia, como la persona que nos la entregó. Recordamos, a veces, apenas fragmentos borrosos, pero rescatamos con nitidez el escenario, el ambiente, la sensación de placer y seguridad al lado de quien nos entregó la palabra con amor. Recordamos también la sensación de estar habitando un espacio de libertad, donde las paredes del mundo se ensanchaban.

Otro beneficio derivado de la literatura es afín con el disfrute y el conocimiento del lenguaje mismo. Esta relación con el lenguaje se hace más estrecha a través de las rimas infantiles, de la poesía y de las canciones. La poesía infantil y las canciones que son a la vez poesía - entregan al niño pequeño el rumor del lenguaje. Musicalidad, cadencia, 
ritmo, melodía, suenan dentro del niño y lo acompañan. El niño que se nutre de versos, ya sean de tradición oral o de autor, es un niño que incorpora en su haber sentidos profundos y simbólicos del lenguaje, de los cuales podrá hacer uso más adelante para expresarse y para crear. La poesía aporta promesas de sentido a través de sus metáforas y de sus imágenes cargadas de múltiples sentidos. Es decir, la poesía habla al inconsciente del niño, haciéndolo sensible a los aspectos más sutiles de la realidad y a la vez estimula su imaginación y le permite apropiarse de sentidos personales debido a sus múltiples y ricos sentidos. Como dice George Jean, la poesía "no es finalmente otra cosa que una provocación para la imaginación." (Jean, 1996, p. 46).

Los cuentos son igualmente necesarios en el desarrollo del niño. Cuentos cortos, cuentos de fórmula, cuentos de nunca acabar provenientes de la tradición oral, cuentos de autor (por lo general expresados a través del Ilamado libro-álbum), o libro de imágenes, el cual utiliza el doble lenguaje: el textual y el visual para construir conjuntamente un relato. Los cuentos, cuando son contados o leídos en viva voz, entregan al niño una cadencia que suspende en el tiempo y transporta al niño a otro mundo. Los cuentos permiten al pequeño lector identificarse con sus personajes. Estos procesos de identificación son necesarios para el desarrollo de la personalidad del niño. Hay también una función socializadora del cuento que presenta al niño diferentes tipos de relaciones entre los personajes, diversos tipos de conflictos y diversas maneras de darles soluciones.

\section{Escolio}

Leyendo el libro de Michèle Petit titulado: Leer el mundo, experiencias actuales de transmisión cultural (2015), comprendí el profundo significado de la labor que hacemos los mediadores de lectura y la importancia de entregar a los niños ese legado simbólico que es la literatura. Petit se refiere a la transmisión cultural y la concibe como una presentación del mundo. Cuando le cantamos a un niño, le contamos, le entregamos un poema, un verso, le estamos presentando el mundo que, a su vez, hemos recibido de quienes nos preceden. Le estamos diciendo al niño, sin decírselo explícitamente, que no está solo, que hace parte de una comunidad, de un nicho que lo acoge y lo protege de los monstruos, de la oscuridad, de las tinieblas más tenebrosas. Lo estamos acogiendo en el seno de la cultura humana. Y esto no es poco. No es solo el afecto doméstico que requiere un niño para crecer sano. Más allá de las faldas de su madre, más allá de la cocina de la casa, de la mano amorosa de su abuela, el niño habita un mundo que para él es desconocido, incierto, amorfo. A través de la transmisión cultural, le entregamos los recursos para habitarlo, ampliamos ese espacio hasta inscribirlo en el espacio simbólico, imaginario, que le permitirá trasegar con seguridad. A través de las adivinanzas, los trabalenguas, los poemas; a través de los cuentos leídos y contados, entremezclados con las rutinas cotidianas; a través de los juegos compartidos, los niños crean los recursos internos necesarios para dar sentido a su vida. Se nutren de palabras para nombrar el mundo, para hacerlo suyo de una manera relacional, analógica, creativa.

Dice Petit glosando de manera muy poética el sentido de esa transmisión cultural:

Te presento a aquellos que te han precedido y el mundo del que vienes, pero te presento también otros universos para que tengas libertad, para que no estés demasiado sometida a tus ancestros. Te doy canciones y relatos para que te los vuelvas a decir a través de la noche, para que no tengas demasiado miedo de la oscuridad y de las sombras. Para que puedas poco a poco prescindir de mí, pensarte como un pequeño sujeto distinto y elaborar luego las múltiples separaciones que te será necesario afrontar. Te entrego trocitos de saber y ficciones para que estés en condiciones de simbolizar la ausencia y hacer frente, tanto como sea posible, a las grandes preguntas humanas, los misterios de la vida y de la muerte, la diferencia de los sexos, el miedo al abandono, a lo desconocido, el amor, la rivalidad. Para que escribas tu propia historia entre las líneas leídas. (2015, p. 25)

Quiero insistir en este concepto de la transmisión cultural porque la literatura infantil ha estado inscrita en nuestro medio, sobre todo en el ámbito escolar. Esto no es grave per se, lo es en la medida en que se la ha instrumentalizado adjudicándole 
funciones que no le pertenecen y que por desgracia la han empobrecido. Se usan los cuentos para enseñar lecciones morales, se los usa para dar mensajes pedagógicos, para enseñar gramática, en fin, son numerosas las funciones de tipo utilitarista, haciendo difícil la comprensión de la función estética y cultural que tienen los libros y la literatura para los niños. La escuela ha hecho un tanto y el mercado otro tanto. $Y$ aquí surge un nuevo escolio: el valor de la gratuidad.

\section{Escolio: necesitamos que nuestros} niños habiten el placer de la gratuidad Dice Martha Nussbaum, filósofa norteamericana:

[...] El niño que se deleita en cuentos y canciones aprende que no todo en la vida humana tiene una utilidad. Adquiere un modo de encarar el mundo que no se concentra exclusivamente en la idea de uso, sino que también es capaz de valorar las cosas por sí mismas. Y el niño traslada esta actitud a su relación con otros seres humanos. No es sólo la capacidad para dotar una forma de vida lo que hace moralmente valiosa la imaginación metafórica, sino la capacidad de encarar los productos de la fantasía como algo que no tiene un fin más allá de sí mismo, que es bueno y deleitable de por sí. El juego y la diversión no son meros aditamentos o suplementos de la vida humana, sino paradigmas para encarar los elementos centrales de la vida. En este sentido, el deleite del lector cobra otra dimensión moral, como preparación para las actividades morales de todo tipo en la vida. (1997, p. 72)

Vivimos en una época en la que la materialidad pareciera controlarlo todo, signada por el consumo y la practicidad, por lo utilitario; un estado de hiper-prosa. Término utilizado por Edgar Morin referido a la construcción de un modo de vida en el cual la racionalización prima por sobre las emociones, un mundo regido por lo monetario, encerrado en un sistema de ideas coherentes y comprobables, dejando por fuera lo sensible, lo intuitivo y lo emocional. Morin rescata el lugar de la poesía como lenguaje de la vida, haciendo del conocimiento un universo poetizable, surgido de la capacidad de construir metáforas, en el que ocupan un lugar privilegiado el asombro, la maravilla, la perplejidad (Morin, 2001).

El placer estético, ese que brinda la experiencia literaria, es gratuito y metafórico. Y hay allí una posibilidad inmensa de que nuestros niños desarrollen relaciones amorosas, desinteresadas, plenas de sentido humano.

Esa relación entre la estética y la ética no es menor y la hemos descuidado mucho. Nos colman los afanes cotidianos, pragmáticos, concretos. Nos signan las relaciones de uso, lo que puedo lograr del otro para mi propio beneficio. Necesitamos crear una ética desinteresada. Cada vez hay menos tiempo para el deleite, para la ensoñación, para el placer del juego, y esto significa menos tiempo y menos espacio para el encuentro con el otro, para la convivencia, para la comprensión de ese otro más allá de mí mismo, de mi propio egoísmo, de mi propio ego.

María Zambrano cuestiona de una manera estética nuestra pobreza: "Una de las más tristes indigencias del tiempo actual es la de las metáforas vivas y actuantes; esas que se imprimen en el ánimo de las gentes y moldean su vida" (Zambrano, 2005).

En mi experiencia como promotora de lectura y como docente, me ha sido muy difícil transmitir los beneficios éticos de la gratuidad, esos de los que habla Nussbaum. Cuando he trabajado con los docentes, con los bibliotecarios, con los líderes culturales, siempre surge de una u otra manera la necesidad de justificar la relación de los niños y jóvenes con la literatura y con la lectura en general. Cuestionarios, pruebas de lectura, análisis, enseñanza gramatical a partir de los textos literarios, búsqueda de personajes principales y secundarios, propósitos sociales de la lectura, réditos pedagógicos, enseñanzas morales o ecológicas; en fin, la lectura concebida como un medio para y no como un fin en sí mismo. Pareciera que hubiéramos perdido la conexión con el juego, con el placer del deleite, con ese margen de libertad que nos otorga la ficción, ese poder atravesar la frontera de la realidad y pasar al otro lado, allí donde la incierto, lo impredecible y lo asombroso puede suceder. Allí donde nos volvemos creadores, artífices de mundos posibles. 
El placer estético transmite una fuerza vital que no se puede medir ni cuantificar. Pongo como ejemplo una escena conmovedora que describe Doris Lessing, en el texto que escribió cuando se supo merecedora del Premio Nobel, acerca de la mujer joven, con dos niños pequeños pegados a sus piernas, haciendo la fila para obtener un poco de agua en medio de una espantosa sequía en África y se encuentra en el mostrador un pedazo de papel arrancado de un libro: es un párrafo de Ana Karenina. Y esa mujer, ávida de agua y de palabra lee, en voz alta y con dificultad:

Verenka lucía muy atractiva con la pañoleta blanca sobre su negra cabellera, rodeada por los niños a quienes atendía con alegría y buen humor y al mismo tiempo visiblemente entusiasmada por la posibilidad de una propuesta de matrimonio que le formularía un hombre a quien apreciaba $[\ldots]$

A la mujer joven la espera un largo y penoso trayecto de regreso a su casa a través del calor y del polvo. Pero ella no se rinde ni se queja, sus pensamientos están ocupados en la historia que acababa de leer. Recordando a Verenka, piensa la joven: "Se parece a mí, con su pañoleta blanca y también porque cuida niños. Yo podría ser ella, esa chica rusa y ese hombre, que la ama y le propondrá matrimonio" .... ¿De dónde sacó la fuerza para regresar a su choza con esperanza? Del impulso vital que le transmitió apenas un párrafo de una obra viva. Y una obra viva es una obra de calidad ${ }^{2}$.

\section{Escolio: la calidad literaria}

El tema de la calidad literaria también merece un escolio. Con el fin de subir los índices de lectura, esta se promueve independientemente de la calidad de lo que se lea. Tanto desde las políticas públicas como desde los afanes del mercado se buscan lectores a como dé lugar. Las editoriales diseñan planes lectores y utilizan todo tipo de estrategias de marketing (hasta algunas poco dignas) para que en las instituciones educativas se "adopten" los libros a granel. Se hacen libros pre-fabricados a partir de

2 Véase Lessing (2013). temas de actualidad, hasta el punto que se ha logrado confundir la literatura con los libros de autoayuda. Se fabrican sagas para aumentar las ventas y se hacen maratones de lectura que Ilenan las estadísticas de libros y de lectores. En todo este afán contable se va desdibujando el valor de la calidad literaria, el valor de la obra de artística.

En este tema de la formación de lectores ¿por qué es importante la calidad?, ¿qué es eso de la calidad?, ¿cómo se mide la calidad de una obra?

La crítica literaria nos ha dado claves para acercarnos a lo que puede aportar calidad a una obra: el manejo del lenguaje, la estructura y la arquitectura de la obra, el ritmo, la caracterización y fuerza de los personajes (si estamos frente a una obra narrativa o dramática); el tiempo, la intertextualidad, la densidad de las palabras, las imágenes poéticas, en fin... Es asunto de los críticos deslindar estos recursos para poder apreciar con fundamento teórico la calidad. Sin embargo, no todos los mediadores (docentes, bibliotecarios, promotores de lectura, madres comunitarias) son ni deben ser críticos literarios. Son y deberían ser lectores, unos buenos lectores, apasionados que se pasean con gusto y familiaridad no solo por la literatura que los alimenta a ellos sino también por los libros para niños. Y en ese recorrido apasionado se van curando los criterios de selección, vamos intuyendo y develando ese misterio aparente de la calidad literaria.

Tuve en mi carrera (estudié literatura) un profesor, el padre Marino Troncoso, el cual me regaló una clave reina para apreciar la calidad: la duración. Explicaba el padre que no se trataba del tiempo en el que transcurría la obra, ni del tiempo histórico, ni del que duraba su lectura... era otra noción de tiempo más subjetiva: el tiempo que duraba la obra en el interior del lector. $Y$ es que eso les pasa a las buenas obras: tienen duración. Habitan y resuenan de múltiples maneras en la interioridad del lector. "Otra vez, otra vez — pide un niño pequeño frente a una historia que le ha gustado-... cuéntamelo de nuevo". Muchas veces los padres o maestros desesperados y sin comprender esa necesidad del niño, lo privan de seguir escuchando, allá en lo profundo, los ecos sonoros, visuales y emocionales de ese cuento que el niño quiere hacer suyo porque lo necesita. Alimento para el alma, pan afecto y literatura. 
No es lo mismo decir que Tina se tiró al río para despedirse que decir:

Al pasar junto al río, Tina no aguantó las ganas de sentirlo otra vez. Sin que nadie lo notara, se fue quedando rezagada y cuando la procesión desapareció en la lejanía, corrió hacia el agua, aventó los zapatos y se sumergió en ella. Tal vez fue el agua la que llamó a las lágrimas que había contenido desde que supo que dejarían el pueblo. Pero ahora podían fluir confundidas con la corriente, como si ella y el río fuesen una sola cosa, una sola entidad acuática que se dolía porque debía partirse en dos, y vivir en adelante destinos diferentes y distantes [...]. (Hiriart, 2001)

Las obras literarias de calidad tienen una materialidad imbricada con el contenido, inseparable de este; una materialidad que hace parte de su sentido profundo, es constitutiva de su sentido. Y es en esa relación entre la forma y el fondo, entre la materialidad y el contenido en que la literatura se juega su dimensión artística y se juega así mismo el efecto estético en el lector. Por eso es triste y pobre que mal alimentemos a los niños con literatura chatarra, privándolos del placer de las texturas, de los sonidos, la musicalidad, el ritmo, que ofrecen los textos bien tejidos.

Reflexionemos ahora por contraste: ¿qué pasa con una obra prefabricada, obvia, que se consume con rapidez y deja poco sabor? Pasa lo mismo que pasa con la comida chatarra: no alimenta y puede hacer daño. Leer estos libros de vez en cuando no es tan grave. Pero que un niño solo lea obras prefabricadas sí lo es. Estas obras están por lo general plagadas de lugares comunes, refuerzan estereotipos retardatarios y privan a los niños del universo metafórico, de las infinitas posibilidades de imaginar y aprender cómo un zorro astuto logra defenderse de los granjeros que lo persiguen y construir un pueblo debajo de la tierra para todos los animales, como en el Súper zorro de Roald Dahl; de sentir compasión por la niña de los fósforos cuando solo le queda una cerilla para calentarse antes de morir por el frío, como ocurre en La niña de los fósforos de Hans Christian Andersen; de Ilorar cuando el topo no encuentra el camino de regreso a su casa en El viento en los sauces; de atravesar Suecia montado en un pato acompañando a Nill Holgersson, o calmando sus pesadillas al descubrir que los monstruos también se lavan los dientes con Tengo miedo, de Ivar Da Coll, por poner algunos ejemplos que me vienen a la mente.

$\mathrm{Y}$ eso es lo que trasmite la verdadera literatura, la que está hecha con el genio del creador y el oficio del artesano.

Forster lo dijo con suma claridad:

Lo maravilloso de toda gran literatura es que transforma al hombre que la lee hasta la condición del hombre que la escribió, y hace nacer en nosotros el estímulo creador. Perdidos en la belleza donde él se hallaba perdido encontramos más de lo que desechó, alcanzamos lo que parece ser nuestro hogar espiritual, y recordamos que no era el orador quien estaba al comienzo sino la Palabra. (2007, p. 57) Bogotá, noviembre 20 de 2017

\section{Referencias}

Forster, E. M. (2007). "Anonimato: una reflexión". En Sobre el oficio literario. Cuadernos de la Palabra. México: Universidad Veracruzana.

Hiriart, B. (2001). Día de muertos. México: Lectorum Publications.

Jean, G. (1990). Los senderos de la imaginación infantil. Los cuentos, los poemas, la realidad. México: Fondo de Cultura Económica.

. (1996). La poesía en la escuela. Hacia una escuela de la poesía. Madrid: Ediciones de la Torre.

Lessing, D. (2013). Discurso al aceptar el Premio Nobel de literatura. Recuperado de: http://bibliotecas.unileon.es/tULEctura/files/2013/11/ Doris Lessing Discurso al aceptar el Premio Nobel de literatura.pdf

Morin, E. (2001). Amor, poesía, sabiduría. Barcelona: Seix Barral.

Nussbaum, M. (1997). Justicia poética. Santiago de Chile: Andrés Bello.

Petit, M. (2015). Leer el mundo. Experiencias actuales de transmisión cultural. Buenos Aires: Fondo de Cultura Económica.

Wikipedia (s.f.). Escolio. Recuperado de https:// es.wikipedia.org/wiki/Escolio

Zambrano, M. (2005). Hacia un saber sobre el alma. Buenos Aires: Losada. 